\title{
The Role of Peroxisome Proliferator-Activated Receptors in the Development and Physiology of Gametes and Preimplantation Embryos
}

\begin{abstract}
Jaou-Chen Huang
Division of Reproductive Endocrinology and Infertility, Department of Obstetrics, Gynecology and Reproductive Sciences, University of Texas Medical School at Houston, 6431 Fannin Street, Houston, TX 77030, USA
\end{abstract}

Correspondence should be addressed to Jaou-Chen Huang, jaou-chen.huang@uth.tmc.edu

Received 22 August 2007; Accepted 4 December 2007

Recommended by Pascal Froment

In several species, a family of nuclear receptors, the peroxisome proliferator-activated receptors (PPARs) composed of three isotypes, is expressed in somatic cells and germ cells of the ovary as well as the testis. Invalidation of these receptors in mice or stimulation of these receptors in vivo or in vitro showed that each receptor has physiological roles in the gamete maturation or the embryo development. In addition, synthetic PPAR $\gamma$ ligands are recently used to induce ovulation in women with polycystic ovary disease. These results reveal the positive actions of PPAR in reproduction. On the other hand, xenobiotics molecules (in herbicides, plasticizers, or components of personal care products), capable of activating PPAR, may disrupt normal PPAR functions in the ovary or the testis and have consequences on the quality of the gametes and the embryos. Despite the recent data obtained on the biological actions of PPARs in reproduction, relatively little is known about PPARs in gametes and embryos. This review summarizes the current knowledge on the expression and the function of PPARs as well as their partners, retinoid X receptors (RXRs), in germ cells and preimplantation embryos. The effects of natural and synthetic PPAR ligands will also be discussed from the perspectives of reproductive toxicology and assisted reproductive technology.

Copyright (c) 2008 Jaou-Chen Huang. This is an open access article distributed under the Creative Commons Attribution License, which permits unrestricted use, distribution, and reproduction in any medium, provided the original work is properly cited.

\section{INTRODUCTION}

Peroxisomes are organelles in eukaryotes that remove toxic substances and break down fatty acid. Peroxisome proliferator-activated receptor $\alpha(\operatorname{PPAR} \alpha)$ was discovered during the search for a compound that increases the proliferation of peroxisomes in mouse liver cells [1]. Subsequently, two additional isotypes, $\operatorname{PPAR} \beta$ (also known as PPAR $\delta$ ) and $\operatorname{PPAR} \gamma$, were discovered. The three PPARs are encoded by different genes. Variants arising from alternative splicing and usage of different promoters have been reported in all three PPARs [2]. Together they form a subfamily within the steroid receptor superfamily. To date, PPARs have been identified in many species, including Xenopus, sea squirt, zebrafish, Aedes aegypti (yellow fever mosquito), Anopheles gambiae (a species complex which contains six vectors of malaria), mouse, rat, hamster, and human (http://www.ensembl.org/index.html).

Since their discovery, a great deal has been learned about $\operatorname{PPAR} \alpha, \operatorname{PPAR} \gamma$, and, to a less extent, $\operatorname{PPAR} \beta / \delta$. The knowledge has been applied to clinical practice: synthetic PPAR $\alpha$ ligands (fibrates) and PPAR $\gamma$ ligands (thiazolidinediones TZD), respectively, are widely used to treat lipid and glucose disorders. In contrast, the use of PPARs to enhance fertility is constrained by our relative meager knowledge regarding PPARs and reproduction. PPAR $\gamma$ activators have recently been used to induce ovulation in women with polycystic ovary disease, a condition of ovulation dysfunction associated with insulin resistance. This review will focus on the roles of PPARs in the development and physiology of gametes and preimplantation embryos. Also included in the discussion are potential impacts of natural or synthetic PPAR ligand on reproduction and the promising benefits of synthetic PPAR ligands in enhancing the success of assisted reproductive technology.

\section{PPARs AND RXRs}

PPARs, similar to steroid and thyroid hormone receptors, are ligand-activated nuclear transcription factors. Unlike steroid 
and thyroid hormone receptors, PPARs were discovered before their functions were fully understood. Over the years, tissue distribution and synthetic ligands, which bind to specific PPAR, helped to elucidate the biological functions of PPARs.

PPARs form heterodimers with another nuclear receptor, retinoid $\mathrm{X}$ receptor (RXR). This interaction occurs in the presence and absence of PPAR ligand. The PPARRXR complex recruits other cofactors before binding to PPAR responsive element (PPRE) at the promoter regions of PPAR-responsive genes. Besides PPARs, RXR also forms heterodimers with other nuclear receptors. RXR has three isotypes: $\operatorname{RXR} \alpha, \operatorname{RXR} \beta$, and $\operatorname{RXR} \gamma$, all of which are activated by 9 -cis-retinoic acid (but not by all-trans retinoic acid) [3]. The 9-cis-retinoic acid was originally considered as the endogenous ligand for RXRs in vivo; but recent reports $[4,5]$ cast considerable doubt that it is the case. Although RXRs exist as three isotypes, they do not confer different functions to PPAR-RXR complexes. The PPAR-RXR complexes are activated by either PPAR or RXR ligand, but simultaneous binding by both ligands elicits more potent activities [6]. A unique feature of $\operatorname{PPAR} \beta / \delta$, not seen in $\operatorname{PPAR} \alpha$ or $\operatorname{PPAR} \gamma$, is its ability to repress the transcriptional activities of $\operatorname{PPAR} \alpha$ and PPAR $\gamma$. This activity is mediated by corepressors recruited by $\operatorname{PPAR} \beta / \delta[7]$.

The DNA sequence of PPRE is typically of a direct repeat 1 (DR1) nuclear receptor in that the PPRE DNA sequence consists of two repeats of AGGTCA separated by one nucleotide (AGGTCA N AGGTCA). Detailed analyses of native PPREs show that the consensus PPRE sequence is $5^{\prime}$ AACTAGGNCA A AGGTCA-3' [6]. The extended $5^{\prime}$ half site, the one imperfect DR1 core, and the adenine as the spacing nucleotide may confer additional selectivity to the binding of PPAR-RXR complex.

\section{DISTRIBUTION AND BIOLOGICAL FUNCTIONS OF PPAR}

The functions of PPARs can be extrapolated from tissue(s) expressing the specific PPAR isotype or from the functions of genes regulated by specific PPAR. PPAR $\alpha$ is expressed most abundantly in brown adipose tissue and liver, followed by the kidney, heart, and skeletal muscle. PPAR $\gamma$ is mainly expressed in adipose tissue and, to a less extent, in the colon, the immune system, and the retina. Both $\operatorname{PPAR} \alpha$ and $\operatorname{PPAR} \gamma$ responsive genes are involved in lipid homeostasis. Therefore, it is not surprising that the main functions of $\operatorname{PPAR} \alpha$ and PPAR $y$ are in glucose and lipid homeostasis $[6,8]$.

On the other hand, the ubiquitous distribution of $\operatorname{PPAR} \beta / \delta$ (although gut, kidney, and heart express higher levels than other tissues) makes it difficult to associate $\operatorname{PPAR} \beta / \delta$ with specific biological function [8]. The multiple functions of PPAR $\beta / \delta$ are revealed by the diverse genes regulated by $\operatorname{PPAR} \beta / \delta$, such as ILK [9], $11 \beta$ hydroxysteroid dehydrogenase II [10], PTEN [9], and $14-3-3 \varepsilon$ [11]. It is worth noting that $14-3-3 \varepsilon$ functions as a protein chaperone. Therefore, $\operatorname{PPAR} \beta / \delta$ is indirectly associated with even more diverse range of functions. Indeed, $\mathrm{PPAR} \beta / \delta$ has been implicated in embryo implantation [12], intestinal adenoma [13], colon cancer [14], skin wound healing [15], hair follicle development [16], and cytoprotection [11].

\section{PPAR LIGANDS}

Natural and synthetic PPAR ligands relevant to this review are listed below. More extensive lists are available in the literature $[6,17]$.

Unsaturated fatty acids are ligands to all PPARs, with PPAR $\alpha$ exhibiting the highest affinity; saturated fatty acids, on the other hand, are not effective PPAR ligands. Eicosanoids derived from arachidonic acid form a unique group of fatty acids that bind to PPARs. They include leukotrienes, hydroxyeicosatetraenoic acids (HETEs) (both are formed via the lipoxygenase pathway), and prostaglandins (PGs) (formed via the cyclooxygenase pathway). Leukotriene B4 and 8(S)-HETE are PPAR $\alpha$ ligand; and 15 -deoxy- $\Delta 12,14-\mathrm{PGJ}_{2}$ (15d-PGJ ${ }_{2}$, a $\mathrm{PGD}_{2}$ derivative) is a $\operatorname{PPAR} \gamma$ ligand. Synthetic PPAR $\alpha$ (fibrates) and PPAR $\gamma$ (TZD) ligands are used to lower blood lipid and glucose, respectively. Prostacyclin $\left(\mathrm{PGI}_{2}\right)$ is a natural PPAR $\beta / \delta$ ligand, indeed the uterine $\mathrm{PGI}_{2}$ generated by cyclooxygenase-2 (COX2) mediates the implantation of embryos via $\operatorname{PPAR} \beta / \delta$ [12]. Synthetic $\mathrm{PGI}_{2}$ analogs, such as iloprost and carbaprostacyclin, may function as $\mathrm{PGI}_{2}$ receptor agonists or $\mathrm{PPAR} \beta / \delta$ ligands. Although iloprost is used as a $\mathrm{PGI}_{2}$ receptor agonist to treat pulmonary hypertension and peripheral vascular diseases, no $\mathrm{PGI}_{2}$ analog has been used as a $\mathrm{PPAR} \beta / \delta$ ligand clinically. A recent report indicates that retinoic acid, in cells with high fatty acid binding protein 5 to retinoic acid binding protein-II ratio, may function as a natural $\mathrm{PPAR} \beta / \delta$ ligand [18]. This finding may have evolutional or developmental significance in germ cell maturation, gamete function, or embryo development. $\mathrm{PGI}_{2}$ and retinoic acid may provide functional redundancy to ensure $\operatorname{PPAR} \beta / \delta$ activation or they may compliment each other to activate $\operatorname{PPAR} \beta / \delta$ in a developmental stage-dependent manner based on the ratio of the two binding proteins.

\section{PPAR LIGANDS IN THE REPRODUCTIVE TRACT}

Zygotes remain in the oviduct after fertilization and develop to morula or early blastocyst stage embryos before entering into the uterus. It is generally accepted that, compared with cultured embryos (derived from fertilized eggs in vitro or flushed from oviducts at earlier developmental stage), in vivo embryos develop better and have less cell death because oviducts protect the embryos and promote their development [19]. The unique environment provided by the oviduct includes oviduct-derived soluble factors and embryo-derived autocrine factors. Both oviducts and embryos are sources of PPAR ligand(s).

Earlier studies show that the oviduct produces abundant $\mathrm{PGE}_{2}$ and $\mathrm{PGF}_{2} \alpha$, which regulate its motility. We serendipitously discovered that human [20] and mouse [21] oviducts produce other eicosanoids that activate PPARs. $\mathrm{PGI}_{2}$ (a PPAR $\beta / \delta$ ligand) is the most abundant product, $\mathrm{PGD}_{2}$ (whose derivative, $15 \mathrm{~d}-\mathrm{PGJ} \mathrm{J}_{2}$, is a PPAR $\gamma$ ligand), and other products derived from the lipoxygenase pathway are 
also produced in substantial amounts. $\mathrm{PGI}_{2}$ synthesis by mouse oviducts is synchronized with estrus cycles (and, thus, the development of preimplantation embryos). Peak $\mathrm{PGI}_{2}$ synthetic capacity coincides with the window of receptivity, that is, between the eight-cell and morula stages $[21,22]$.

Recent reports indicate that human [23] and mouse [24, 25] preimplantation embryos express COX isoenzymes and synthesize eicosanoids. $\mathrm{PGI}_{2}$ is the most abundant metabolite when radio-labeled arachidonic acid is incubated with blastocyst-stage mouse embryos. Other eicosanoids, such as HETEs and $\mathrm{PGD}_{2}$ are also produced by mouse blastocysts [24].

\section{RXR IN GAMETES AND PREIMPLANTATION EMBRYOS}

Gametes and preimplantation embryos express RXRs. Whereas RXR $\gamma$-null mice are normal [26], $\operatorname{RXR} \alpha$ - [27] and $\mathrm{RXR} \beta$-null mice [28] have distinctive phenotypes. Gene knockout studies show that spermatogenesis requires $\mathrm{RXR} \beta$. Similarly, oocyte development may be modulated by RXR, which is expressed in both granulosa-cumulus cells and oocytes. Finally, the quality of embryo development may be associated with RXR expression.

\subsection{RXR in gametes}

$\operatorname{RXR} \alpha$ and $\operatorname{RXR} \beta$ are expressed in human cumulus granulosa cells [29] and bovine oocytes [30]. Although the initial reports on $\operatorname{RXR} \alpha$ [27] and $\operatorname{RXR} \beta$ [28] null mice did not include a description of female reproduction (such as follicular development and ovulation), the localization of $\operatorname{RXR} \alpha$ and $\beta$ in the ovary supports their roles in follicular maturation and oocyte function. RXR may regulate oocyte development directly (via modulating steroidogenesis in the granulosa cells) or indirectly (by affecting oocyte gene transcription) [31]. It is likely that female mice with targeted RXR deletion may suffer subfertility.

The male sterility observed in $\operatorname{RXR} \beta$-null mice [28] underscores the essential role of RXR (and its functional partner) in spermatogenesis. In mouse testes, retinoic acid receptors (RARs) and RXR are expressed in well-defined cell populations: $\operatorname{RAR} \alpha$ and $\operatorname{RXR} \beta$ in Sertoli cells, $\operatorname{RAR} \beta, \operatorname{RXR} \alpha$, and RXR $\gamma$ in steps 7 and 8 spermatids, and RAR $\gamma$ in spermatogonia. Mouse spermatocytes, however, do not express RARs [32]. Although $\operatorname{RAR} \beta, \operatorname{RXR} \alpha$, and $\operatorname{RXR} \gamma$ are coexpressed in step 7 and 8 spermatids, RAR $\beta$ may not functionally couple with either $\operatorname{RXR} \alpha$ or $\operatorname{RXR} \gamma$, because $\operatorname{RAR} \beta$-, $\operatorname{RXR} \gamma$-, and $\mathrm{RAR} \beta / \mathrm{RXR} \gamma$-null mice do not display reproductive defects [32]. On the other hand, $\operatorname{RXR} \beta$ and $\operatorname{RAR} \alpha$ may form heterodimer and control spermiation in vivo because both are coexpressed in Sertoli cells and invalidation of either gene in mice leads to similar phenotype [32]. RXR $\beta$-null males are sterile due to oligoasthenoteratozoospermia caused by failed spermatid release (from the germinal epithelium) and abnormal sperm acrosomes and tails [27]. In Sertoli cells, the function of $\operatorname{RXR} \beta$ (coupled with $\operatorname{RAR} \alpha$ ) may involve lipid metabolism or transport, because they progressively accumulate lipids (which are unsaturated triglycerides) in $\operatorname{RXR} \beta$ - null mice. In older $\mathrm{RXR} \beta$-null males, germ cells degenerate completely and seminiferous tubules are filled with lipid vacuoles [27]. RAR $\alpha$ homozygous mutant [33] and mice with targeted RAR $\alpha$ ablation in Sertoli cells [34] display similar phenotype. Both have testicular degeneration, failed spermiation, epithelial vacuolation, germ cell desquamation, and apoptosis [34]. Although there is no report concerning RXR expression in spermatozoa, it can be inferred that human sperm express RXR because human sperm express PPAR $\gamma$ (which forms functional complex with RXR) and PPAR $\gamma$ ligand enhances their activities [35].

\section{2. $R X R$ in preimplantation embryos}

The development of preimplantation embryos was not described in the initial reports describing $\operatorname{RXR} \alpha-$ [27] and RXR $\beta$ - [28] null mice. However, available information in the literature shows that preimplantation embryos express RXRs. Transcripts of $\operatorname{RXR} \alpha, \operatorname{RXR} \beta$, and $\operatorname{RXR} \gamma$ are expressed in zebrafish embryos at 1.5 hour postfertilization [36]. $\operatorname{RXR} \alpha$, $\mathrm{RXR} \beta$, and $\mathrm{RALDH}_{2}$ (one of the two enzymes oxidizing retinol to retinoic acid) are detected in all stages of preimplantation bovine embryos, including blastocysts which express $\operatorname{RXR} \beta$ protein in the inner cell mass and the trophectoderm [30]. $\operatorname{RXR} \alpha, \beta$, and $\gamma$ transcripts in preimplantation bovine embryos are likely of maternal origin because eight-cell stage and earlier embryos have significantly higher RXR levels than later stage embryos [37]. Furthermore, RXRs may be essential for optimal embryo development because "good-quality" embryos express significantly higher levels of RXR transcripts than "bad-quality" embryos [37]. It can be summarized that RXR expression in preimplantation embryos described above is corroborated by the expression of its partner, PPAR (discussed later). Furthermore, RXR (partners with PPAR or RAR) is crucial to normal embryo development because (1) early stage embryos contain high levels of maternal RXR mRNA, and (2) "good-quality" embryos express higher RXR mRNA levels.

\section{PPAR IN GAMETES AND PREIMPLANTATION EMBRYOS}

Compared with their role in postimplantation embryo development, the roles of PPARs in fertilization, implantation, and embryo development are less well defined. Available information does suggest that gametes and preimplantation embryos express functional PPARs and that PPAR activation optimizes their functions.

\subsection{PPAR and gametes}

All three PPAR isotypes are expressed in somatic and germ cells of the testis. In rat, PPAR $\alpha$ and $\beta / \delta$ are expressed in Leydig cells and Sertoli cells [38]. In human, PPAR $\gamma 1$ message is detected in the testis [39]. In mouse, both PPAR $\alpha$ and $\gamma$ are expressed in Sertoli cells [40], and PPAR $\beta / \delta$ is expressed in spermatids and spermatocytes [41]. The expression of PPAR $\beta / \delta$ in mouse spermatids and spermatocytes is further supported by the expression of $S s m$, a novel PPAR $\beta / \delta$ 
target gene, in mouse testis [42]. The functionality of PPAR $\alpha$ in Sertoli cells is confirmed by its nuclear translocation in response to a selective PPAR $\alpha$ ligand, Wy-14,643 [40]. These findings suggest that PPARs (in Sertoli cells and Leydig cells) provide an environment for spermatogenesis and may be directly involved in germ cell maturation. PPAR may regulate germ cell maturation in a stage-dependent fashion. In zebrafish, PPAR $\gamma$ is expressed in spermatogonia but not in spermatocytes [43].

PPAR ligand affects spermatogenesis and sperm activities. $\mathrm{Di}(n$-butyl $)$ phthalate, a PPAR activator, modulates the expression of genes related to spermatogenesis and steroidogenesis and causes testicular atrophy in rats [44]. In contrast, the capacitation, acrosome reaction, and motility of ejaculated human sperm are enhanced by a treatment with rosiglitazone (a synthetic PPAR $\gamma$ ligand) or 15d-PGJ2 (a natural PPAR $\gamma$ ligand) [35]. Since germ cells express all three PPAR isotypes, the expression and function of two other PPAR isotypes, $\operatorname{PPAR} \alpha$ and $\beta / \delta$, in mature spermatozoa warrant further investigation.

In several species including rat, all three PPAR isotypes are detected in the ovary [2]. PPAR $\gamma$, which has been studied more extensively than the other two isotypes, is detected in the mouse, rat, pig, sheep, cow, and human ovary. PPAR $\gamma$ is expressed strongly in the granulosa cells of rat [2], mouse [41], and sheep [45], as well as in oocytes from cattle [30], zebrafish [43], Xenopus [46], and human [47]. PPAR $\gamma$ is detected in different classes of follicles (primary/secondary to preovulatory follicles) and its expression increases with the development of follicles. After the LH surge, PPAR $\gamma$ mRNA expression is downregulated [2]. Activation of PPAR $\gamma$ by natural and synthetic ligands in the granulosa cells appears to regulate the synthesis of steroid hormones. Thus, PPAR $\gamma$ may be indirectly involved in oocyte maturation via the granulosa cells. Indeed, disruption of PPAR $\gamma$ gene in the ovary using cre/loxP technology led to female subfertility [48]. On the other hand, PPARs may be directly involved in oocyte maturation. Indeed, it has been reported that rosiglitazone, a synthetic PPAR $\gamma$ ligand, at $100 \mu \mathrm{M}$ stimulates AMP-activated protein kinase (AMPK) and enhances the meiotic resumption of mouse oocytes [42].

\subsection{PPAR and preimplantation embryos}

Preimplantation bovine and mouse embryos express PPAR $\gamma$ and $\mathrm{PPAR} \beta / \delta$, respectively. Beginning at two-cell stage and throughout the preimplantation period, bovine embryos express PPAR $\gamma$. Blastocyst stage bovine embryos express PPAR $\gamma$ in the inner cell mass and the trophectoderm [30]. Mouse embryos express PPAR $\beta / \delta$ detectable by immunohistochemistry at two-cell stage [25] or eight-cell stage [22] and throughout the preimplantation period. Mouse blastocysts also express PPAR $\beta / \delta$ in the inner cell mass and the trophectoderm [22].

Although preimplantation embryo development and implantation were not specifically examined in the initial report regarding PPAR $\beta / \delta$-null mouse, the report provides a hint of the impacts of PPAR $\beta / \delta$ deficiency [49]. The genotypic distribution of embryos on gestation day 9.5 shows that
$\operatorname{PPAR} \beta / \delta-/-$ embryos are underrepresented: $\mathrm{PPAR} \beta / \delta-/-$ embryos represent $16 \%(3 / 19)$ and $38 \%(3 / 8)$ of embryos from $\operatorname{PPAR} \beta / \delta+1-\mathrm{x} \operatorname{PPAR} \beta / \delta+/-$ and $\operatorname{PPAR} \beta / \delta-1-\mathrm{x}$ $\operatorname{PPAR} \beta / \delta+/-$ mating, respectively. This represents a $36 \%$ (i.e., $25 \%$ versus $16 \%$ ) and a $24 \%$ (i.e., $50 \%$ versus $38 \%$ ) deviation from the expected Mendelian frequency. Loss of $\operatorname{PPAR} \beta / \delta-/-$ embryos prior to gestation day 9.5 may occur at any stage including ovulation, fertilization, preimplantation period, implantation, and postimplantation period up to gestation day 9.5. The results of our study show that $\mathrm{PPAR} \beta / \delta$ ablation adversely affects preimplantation embryo development and, consequently, implantation [22]. Compared with wild-type embryos, PPAR $\beta / \delta-/-$ embryos show developmental delay as early as 48 hours after two-cell stage embryos are harvested. The gap widens in the subsequent 48 hours. At 96 hours after the harvest of two-cell embryos, $100 \%$ of wild-type embryos have reached or passed the blastocyst stage (versus $65 \% \operatorname{PPAR} \beta / \delta-/-$ embryos), and $85 \%$ of wild-type embryos have undergone hatching or hatched completely (versus 28\% PPAR $\beta / \delta-/-$ embryos). Consequently, $\operatorname{PPAR} \beta / \delta-/-$ embryos implant less effectively than wild-type embryos ( $28 \%$ versus $44 \%$ ). We also found that $\operatorname{PPAR} \beta / \delta-/-$ embryos have decreased embryonic cell proliferation compared with that observed in wild-type embryos. These results suggest that $\mathrm{PPAR} \beta / \delta$ activation via endogenous $\mathrm{PPAR} \beta / \delta$ ligand, such as $\mathrm{PGI}_{2}[24]$ and/or retinoic acid [18], confers the "basal" momentum (including cell proliferation and possibly other functions) to preimplantation embryos and propels them through various stages of development.

In addition to providing a "basal" momentum of embryo development via endogenous $\operatorname{PPAR} \beta / \delta$ ligand, $\operatorname{PPAR} \beta / \delta$ activation by synthetic ligand further enhances the development and the implantation of cultured embryos. Both L165041 (a synthetic PPAR $\beta / \delta$ ligand) and iloprost (a stable $\mathrm{PGI}_{2}$ analog) enhance complete embryo hatching in a concentration-dependent manner $[22,50,51]$. Embryos preconditioned with L-165041 or iloprost show higher implantation rates when transferred to gestational carriers $[22,52]$. These results suggest that cultured embryos do not reach their full developmental potential due to insufficient endogenous $\operatorname{PPAR} \beta / \delta$ ligands or lack of exogenous $\operatorname{PPAR} \beta / \delta$ ligands normally provided by the oviduct. Embryos exposed to $\operatorname{PPAR} \beta / \delta$ ligand have increased embryonic cell proliferation compared with controlled embryos [22].

\section{PPAR AND REPRODUCTIVE TOXICOLOGY}

PPAR activators are found in herbicides, industrial plasticizers (for a brief review see [53]), and personal care products such as hair spray and solvent for perfumes [54]. Di( $n$-butyl) phthalate, a PPAR $\gamma$ activator found in plasticizers and personal care products, may cause male infertility by altering hormones involved in steroidogenesis and spermatogenesis [44]. Other potential PPAR activators posing reproductive toxicology concerns are pharmaceutical agents used to lower lipids and blood glucose. Rosiglitazone (a TZD for diabetes) may activate PPAR $\gamma$ ligand and enhance sperm activities in men [35] or, depending on its concentration, may enhance 
meiosis resumption of oocytes or induce oocyte degeneration in women [55]. Nonsteroidal anti-inflammatory drugs, such as Motrin, which blocks PG synthesis, pose reproductive hazards through a different mechanism. Decreased PG (such as $\mathrm{PGI}_{2}$ ) production may adversely affect embryo development and implantation.

On the other hand, PPARs may be exploited to enhance the success of assisted reproductive technology. The fertilization potentials of human sperm in in vitro fertilization (IVF) or other assisted reproductive technologies, such as artificial insemination, may be enhanced by incubating sperm with synthetic PPAR $y$ ligands. The development and implantation of IVF embryos may be augmented by supplementing culture media with $\mathrm{PGI}_{2}$ analogs, synthetic $\mathrm{PPAR} \beta / \delta$ ligand, or retinoic acid. However, potential long-term adverse effects are unknown. Large-scale clinical trials of sufficient power are needed to validate the benefits and to assess the harms.

\section{CONCLUSION}

The literature on PPARs in gametes and preimplantation embryos is relatively limited. Nonetheless, the consensus is that PPAR serves to optimize gamete function and embryo development. Further studies are needed to shed more light on the physiological roles of PPARs in reproduction. The knowledge gained will help us avoid potential reproductive hazards and augment the success of assisted reproductive technologies.

\section{REFERENCES}

[1] I. Issemann and S. Green, "Activation of a member of the steroid hormone receptor superfamily by peroxisome proliferators," Nature, vol. 347, no. 6294, pp. 645-650, 1990.

[2] C. M. Komar, "Peroxisome proliferator-activated receptors (PPARs) and ovarian function-implications for regulating steroidogenesis, differentiation, and tissue remodeling," Reprod Biol Endocrinol, vol. 3, p. 41, 2005.

[3] D. J. Mangelsdorf, C. Thummel, M. Beato, et al., "The nuclear receptor superfamily: the second decade," Cell, vol. 83 , no. 6 , pp. 835-839, 1995.

[4] F. A. Mic, A. Molotkov, D. M. Benbrook, and G. Duester, "Retinoid activation of retinoic acid receptor but not retinoid $\mathrm{X}$ receptor is sufficient to rescue lethal defect in retinoic acid synthesis," Proceedings of the National Academy of Sciences of the United States of America, vol. 100, no. 12, pp. 7135-7140, 2003.

[5] G. Wolf, "Is 9-cis-retinoic acid the endogenous ligand for the retinoic acid-X receptor?” Nutrition Reviews, vol. 64, no. 12, pp. 532-538, 2006.

[6] B. Desvergne and W. Wahli, "Peroxisome proliferatoractivated receptors: nuclear control of metabolism," Endocrine Reviews, vol. 20, no. 5, pp. 649-688, 1999.

[7] Y. Shi, M. Hon, and R. M. Evans, "The peroxisome proliferator-activated receptor $\delta$, an integrator of transcriptional repression and nuclear receptor signaling," Proceedings of the National Academy of Sciences of the United States of America, vol. 99, no. 5, pp. 2613-2618, 2002.

[8] S. Kersten, B. Desvergne, and W. Wahli, "Roles of PPARS in health and disease," Nature, vol. 405, no. 6785, pp. 421-424, 2000 .
[9] N. Di-Poi, N. S. Tan, L. Michalik, W. Wahli, and B. Desvergne, "Antiapoptotic role of PPAR $\beta$ in keratinocytes via transcriptional control of the Aktl signaling pathway," Molecular Cell, vol. 10, no. 4, pp. 721-733, 2002.

[10] L. Julan, H. Guan, J. P. van Beek, and K. Yang, "Peroxisome proliferator-activated receptor $\delta$ suppresses $11 \beta$ hydroxysteroid dehydrogenase type 2 gene expression in human placental trophoblast cells," Endocrinology, vol. 146, no. 3, pp. 1482-1490, 2005.

[11] J.-Y. Liou, S. Lee, D. Ghelani, N. Matijevic-Aleksic, and K. K. Wu, "Protection of endothelial survival by peroxisome proliferator-activated receptor- $\delta$ mediated 14-3-3 upregulation," Arteriosclerosis, Thrombosis, and Vascular Biology, vol. 26, no. 7, pp. 1481-1487, 2006.

[12] H. Lim, R. A. Gupta, W. G. Ma, et al., "Cyclo-oxygenase2-derived prostacyclin mediates embryo implantation in the mouse via PPAR $\delta$," Genes \& development, vol. 13, no. 12, pp. 1561-1574, 1999.

[13] R. A. Gupta, D. Wang, S. Katkuri, H. Wang, S. K. Dey, and R. N. DuBois, "Activation of nuclear hormone receptor peroxisome proliferator-activated receptor- $\delta$ accelerates intestinal adenoma growth," Nature Medicine, vol. 10, pp. 245-247, 2004.

[14] R. A. Gupta, J. Tan, W. F. Krause, et al., "Prostacyclin-mediated activation of peroxisome proliferator-activated receptor $\delta$ in colorectal cancer," Proceedings of the National Academy of Sciences of the United States of America, vol. 97, no. 24, pp. 1327513280, 2000.

[15] N. Di-Poi, L. Michalik, N. S. Tan, B. Desvergne, and W. Wahli, "The anti-apoptotic role of PPAR $\beta$ contributes to efficient skin wound healing," Journal of Steroid Biochemistry and Molecular Biology, vol. 85, no. 2-5, pp. 257-265, 2003.

[16] N. Di-Poi, C. Y. Ng, N. S. Tan, et al., "Epithelium-mesenchyme interactions control the activity of peroxisome proliferatoractivated receptor $\beta / \delta$ during hair follicle development," Molecular and Cellular Biology, vol. 25, no. 5, pp. 1696-1712, 2005.

[17] B. M. Forman, J. Chen, and R. M. Evans, "Hypolipidemic drugs, polyunsaturated fatty acids, and eicosanoids are ligands for peroxisome proliferator-activated receptors $\alpha$ and $\delta$," Proceedings of the National Academy of Sciences of the United States of America, vol. 94, pp. 4312-4317, 1997.

[18] T. T. Schug, D. C. Berry, N. S. Shaw, S. N. Travis, and N. Noy, "Opposing effects of retinoic acid on cell growth result from alternate activation of two different nuclear receptors," Cell, vol. 129 , no. 4, pp. 723-733, 2007.

[19] K. Hardy and S. Spanos, "Growth factor expression and function in the human and mouse preimplantation embryo," Journal of Endocrinology, vol. 172, no. 2, pp. 221-236, 2002.

[20] J.-C. Huang, F. Arbab, K. J. Tumbusch, J. S. Goldsby, N. Matijevic-Aleksic, and K. K. Wu, "Human Fallopian tubes express prostacyclin (PGI) synthase and cyclooxygenases and synthesize abundant PGI," Journal of Clinical Endocrinology \& Metabolism, vol. 87, no. 9, pp. 4361-4368, 2002.

[21] J.-C. Huang, J. S. Goldsby, F. Arbab, Z. Melhem, N. Aleksic, and $\mathrm{K} . \mathrm{K} . \mathrm{Wu}$, "Oviduct prostacyclin functions as a paracrine factor to augment the development of embryos," Human Reproduction, vol. 19, no. 12, pp. 2907-2912, 2004.

[22] J.-C. Huang, W. S. Wun, J. S. Goldsby, I. C. Wun, D. Noorhasan, and K. K. Wu, "Stimulation of embryo hatching and implantation by prostacyclin and peroxisome proliferator-activated receptor $\delta$ activation: implication in IVF," Human Reproduction, vol. 22, no. 3, pp. 807-814, 2007. 
[23] H. Wang, Y. Wen, S. Mooney, B. Behr, and M. L. Polan, "Phospholipase $\mathrm{A}_{2}$ and cyclooxygenase gene expression in human preimplantation embryos," Journal of Clinical Endocrinology \& Metabolism, vol. 87, no. 6, pp. 2629-2634, 2002.

[24] J.-C. Huang, W.-S. A. Wun, J. S. Goldsby, N. Matijevic-Aleksic, and K. K. Wu, "Cyclooxygenase-2-derived endogenous prostacyclin enhances mouse embryo hatching," Human Reproduction, vol. 19, no. 12, pp. 2900-2906, 2004.

[25] P. L. Pakrasi and A. K. Jain, "Evaluation of cyclooxygenase 2 derived endogenous prostacyclin in mouse preimplantation embryo development in vitro," Life Sciences, vol. 80, no. 16, pp. 1503-1507, 2007.

[26] W. Krezel, V. Dupe, M Mark, A. Dierich, P. Kastner, and P. Chambon, "RXR gamma null mice are apparently normal and compound RXR alpha +/-/RXR beta -/-/RXR gamma -/- mutant mice are viable," Proceedings of the National Academy of Sciences of the United states of America, vol. 93, no. 17, pp. 9010-9014, 1996.

[27] P. Kastner, J. M. Grondona, M. Mark, et al., "Genetic analysis of RXR $\alpha$ developmental function: convergence of RXR and RAR signaling pathways in heart and eye morphogenesis," Cell, vol. 78, no. 6, pp. 987-1003, 1994.

[28] P. Kastner, M. Mark, M. Leid, et al., "Abnormal spermatogenesis in RXR $\beta$ mutant mice," Genes \& development, vol. 10, pp. 80-92, 1996.

[29] M. Mohan, N. R. Thirumalapura, and J. Malayer, "Bovine cumulus-granulosa cells contain biologically active retinoid receptors that can respond to retinoic acid," Reproductive Biology and Endocrinology, vol. 1, p. 104, 2003.

[30] M. Mohan, J. R. Malayer, R. D. Geisert, and G. L. Morgan, "Expression patterns of retinoid X receptors, retinaldehyde dehydrogenase, and peroxisome proliferator activated receptor $\gamma$ in bovine preattachment embryos," Biology of Reproduction, vol. 66, no. 3, pp. 692-700, 2002.

[31] S. Minucci, J. Wong, J. C. G. Blanco, Y.-B. Shi, A. P. Wolffe, and K. Ozato, "Retinoid receptor-induced alteration of the chromatin assembled on a ligand-responsive promoter in Xenopus oocytes," Molecular Endocrinology, vol. 12, no. 3, pp. 315-324, 1998.

[32] N. Vernet, C. Dennefeld, C. Rochette-Egly, et al., "Retinoic acid metabolism and signaling pathways in the adult and developing mouse testis," Endocrinology, vol. 147, no. 1, pp. 96110, 2006.

[33] T. Lufkin, D. Lohnes, M. Mark, et al., "High postnatal lethality and testis degeneration in retinoic acid receptor $\alpha$ mutant mice," Proceedings of the National Academy of Sciences of the United States of America, vol. 90, pp. 7225-7229, 1993.

[34] N. Vernet, C. Dennefeld, F. Guillou, P. Chambon, N. B. Ghyselinck, and M. Mark, "Prepubertal testis development relies on retinoic acid but not rexinoid receptors in Sertoli cells," EMBO Journal, vol. 25, no. 24, pp. 5816-5825, 2006.

[35] S. Aquila, D. Bonofiglio, M. Gentile, et al., "Peroxisome proliferator-activated receptor (PPAR) $\gamma$ is expressed by human spermatozoa: its potential role on the sperm physiology," Journal of Cellular Physiology, vol. 209, no. 3, pp. 977-986, 2006.

[36] A. Tallafuss, L. A. Hale, Y.-L. Yan, L. Dudley, J. S. Eisen, and J. H. Postlethwait, "Characterization of retinoid-X receptor genes rxra, rxrba, rxrbb and rxrg during zebrafish development," Gene Expression Patterns, vol. 6, no. 5, pp. 556-565, 2006.

[37] S. Mamo, S. Ponsuksili, K. Wimmers, M. Gilles, and K. Schellander, "Expression of retinoid $\mathrm{X}$ receptor transcripts and their significance for developmental competence in in vitroproduced pre-implantation-stage bovine embryos," Reproduction in Domestic Animals, vol. 40, no. 2, pp. 177-183, 2005.

[38] O. Braissant, F. Foufelle, C. Scotto, M. Dauca, and W. Wahli, "Differential expression of peroxisome proliferator-activated receptors (PPARs): tissue distribution of PPAR- $\alpha,-\beta$, and $-\gamma$ in the adult rat," Endocrinology, vol. 137, pp. 354-366, 1996.

[39] A. Elbrecht, Y. Chen, C. A. Cullinan, et al., "Molecular cloning, expression and characterization of human peroxisome proliferator activated receptors $\gamma 1$ and $\gamma 2$," Biochemical and Biophysical Research Communications, vol. 224, no. 2, pp. 431437, 1996.

[40] N. Bhattacharya, J. M. Dufour, M. N. Vo, J. Okita, R. Okita, and K. H. Kim, "Differential effects of phthalates on the testis and the liver," Biology of Reproduction, vol. 72, pp. 745-754, 2005.

[41] H. Higashiyama, A. N. Billin, Y. Okamoto, M. Kinoshita, and S. Asano, "Expression profiling of peroxisome proliferatoractivated receptor- $\delta$ (PPAR- $\delta$ ) in mouse tissues using tissue microarray," Histochemistry and Cell Biology, vol. 127, no. 5, pp. 485-494, 2007.

[42] K. Han, H. Song, I. Moon, et al., "Utilization of DR1 as true RARE in regulating the $S \mathrm{sm}$, a novel retinoic acid-target gene in the mouse testis," Journal of Endocrinology, vol. 192, pp. 539-551, 2007.

[43] A. Ibabe, M. Grabenbauer, E. Baumgart, H. D. Fahimi, and M. P. Cajaraville, "Expression of peroxisome proliferatoractivated receptors in zebrafish (Danio rerio)," Histochemistry and Cell Biology, vol. 118, no. 3, pp. 231-239, 2002.

[44] J. Y. Ryu, B. M. Lee, S. Kacew, and H. S. Kim, "Identification of differentially expressed genes in the testis of Sprague-Dawley rats treated with di(n-butyl) phthalate," Toxicology, vol. 234, no. 1-2, pp. 103-112, 2007.

[45] P. Froment, S. Fabre, J. Dupont, et al., "Expression and functional role of peroxisome proliferator-activated receptor- $\gamma$ in ovarian folliculogenesis in the sheep," Biology of Reproduction, vol. 69, pp. 1665-1674, 2003.

[46] C. Dreyer and H. Ellinger-Ziegelbauer, "Retinoic acid receptors and nuclear orphan receptors in the development of Xenopus laevis," International Journal of Developmental Biology, vol. 40, no. 1, pp. 255-262, 1996.

[47] J. R. Wood, D. A. Dumesic, D. H. Abbott, and J. F. Strauss III, "Molecular abnormalities in oocytes from women with polycystic ovary syndrome revealed by microarray analysis," Journal of Clinical Endocrinology \& Metabolism, vol. 92, no. 2, pp. 705-713, 2007.

[48] Y. Cui, K. Miyoshi, E. Claudio, et al., "Loss of the peroxisome proliferation-activated receptor $\gamma(\operatorname{PPAR} \gamma)$ does not affect mammary development and propensity for tumor formation but leads to reduced fertility," Journal of Biological Chemistry, vol. 277, no. 20, pp. 17830-17835, 2002.

[49] Y. Barak, D. Liao, W. He, et al., "Effects of peroxisome proliferator-activated receptor $\delta$ on placentation, adiposity, and colorectal cancer," Proceedings of the National Academy of Sciences of the United States of America, vol. 99, no. 1, pp. 303308, 2002.

[50] J.-C. Huang, W.-S. A. Wun, J. S. Goldsby, I. C. Wun, S. M. Falconi, and $\mathrm{K} . \mathrm{K}$. Wu, "Prostacyclin enhances embryo hatching but not sperm motility," Human Reproduction, vol. 18, no. 12, pp. 2582-2589, 2003.

[51] C.-H. Liu, M.-S. Lee, C.-H. Hsieh, C.-C. Huang, H.-M. Tsao, and Y.-S. Hsieh, "Prostacyclin enhances mouse embryo development and hatching but not increased embryonic cell 
number and volume," Fertility and Sterility, vol. 86, no. 4, pp. 1047-1052, 2006.

[52] J.-C. Huang, J. S. Goldsby, and W.-S.A. Wun, "Prostacyclin enhances the implantation and live birth potentials of mouse embryos," Human Reproduction, vol. 19, no. 8, pp. 1856-1860, 2004.

[53] E. A. Lock, A. M. Mitchell, and C. R. Elcombe, "Biochemical mechanisms of induction of hepatic peroxisome proliferation," Annual Review of Pharmacology and Toxicology, vol. 29, pp. $145-163,1989$.

[54] R. H. McKee, J. H. Butala, R. M. David, and G. Gans, "NTP center for the evaluation of risks to human reproduction reports on phthalates: addressing the data gaps," Reproductive Toxicology, vol. 18, no. 1, pp. 1-22, 2004.

[55] J. Chen, E. Hudson, M. M. Chi, et al., "AMPK regulation of mouse oocyte meiotic resumption in vitro," Developmental Biology, vol. 291, no. 2, pp. 227-238, 2006. 


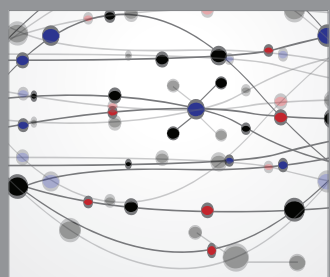

The Scientific World Journal
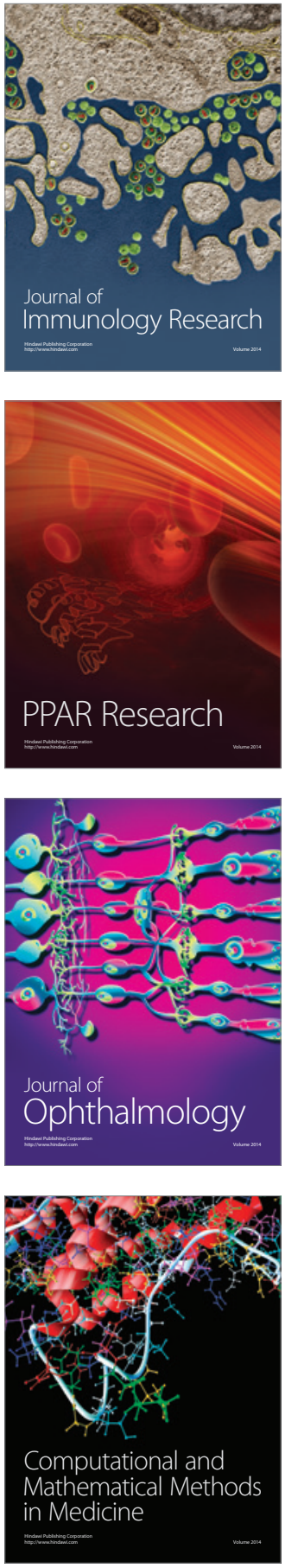

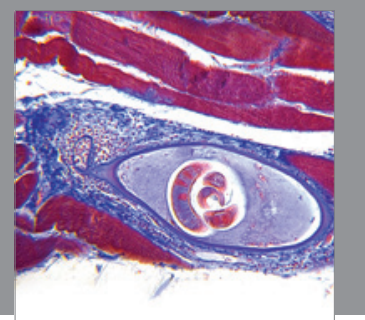

Gastroenterology

Research and Practice
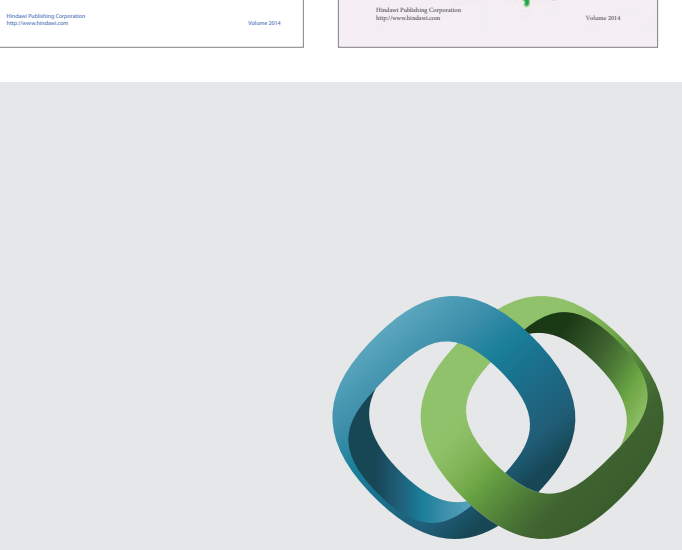

\section{Hindawi}

Submit your manuscripts at

http://www.hindawi.com
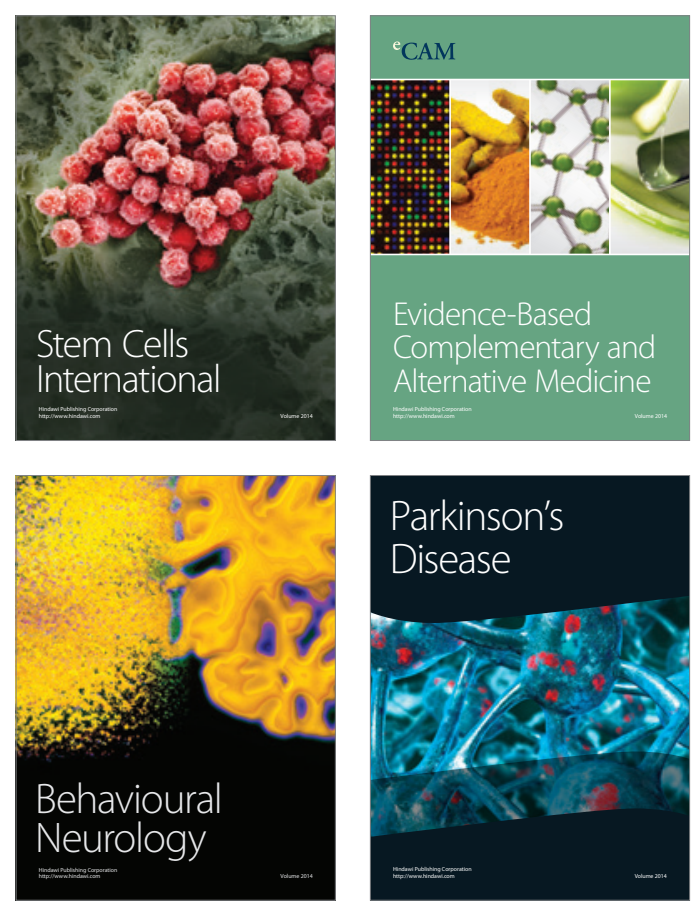

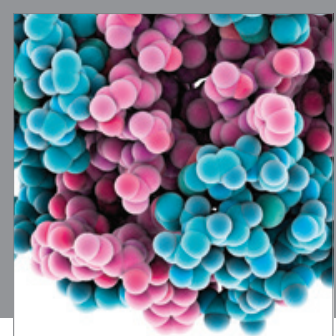

Journal of
Diabetes Research

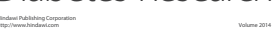

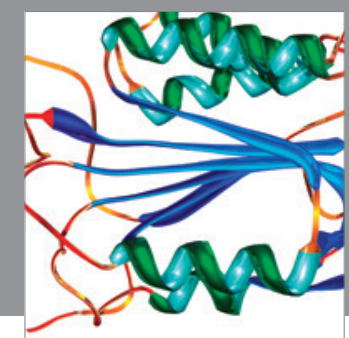

Disease Markers
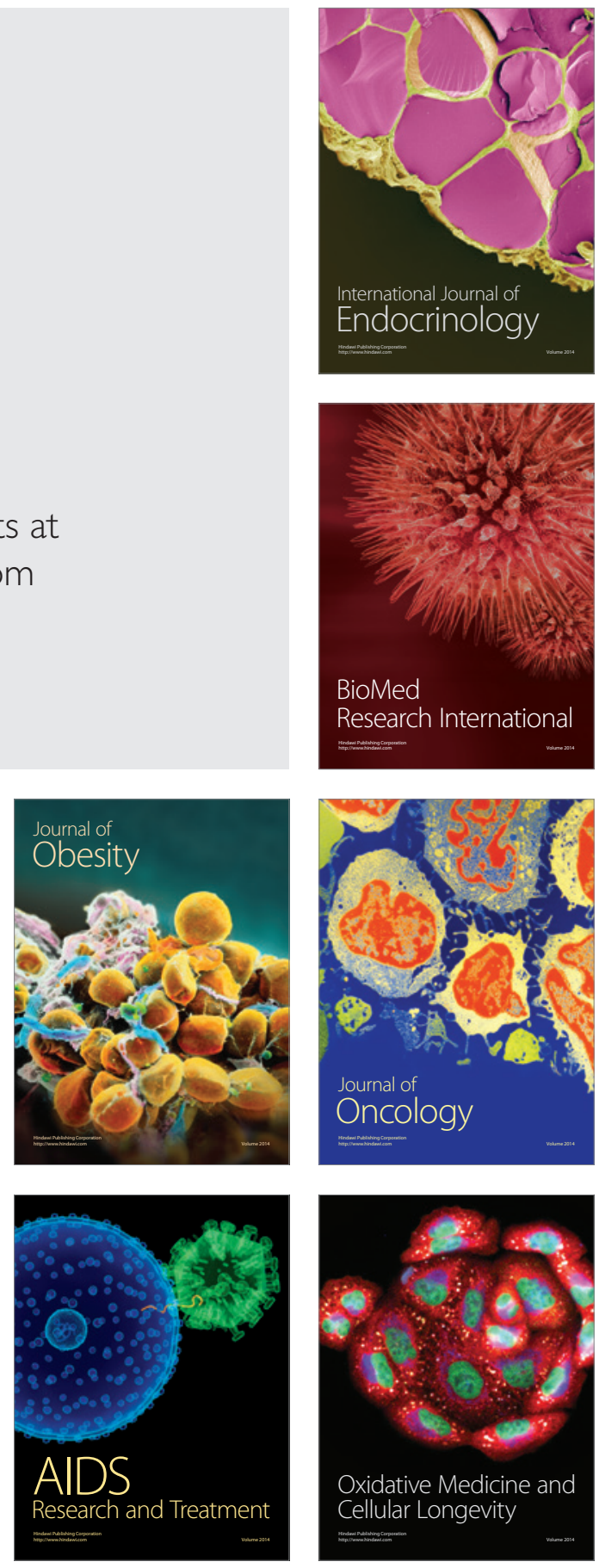